\title{
EL DESARROLLO DEL MOVIMIENTO FEMENINO PALESTINO DESDE LOS INICIOS DEL SIGLO XX HASTA LA ACTUALIDAD
}

\author{
Duha AHMED \\ Universidad de Jaén (España) \\ f_duha@live.com
}

\section{THE DEVELOPMENT OF THE FEMINIST PALESTINIAN MOVEMENT FROM THE BEGINNING OF THE XX CENTURY TILL NOWADAYS}

Resumen: El objetivo de este estudio es poner de relieve el importante papel que han desempeñado las mujeres palestinas en la vida social y política de su país desde comienzos del siglo XX (incluso, también, a finales del XIX) hasta la actualidad. El Movimiento Femenino Palestino fue, y sigue siendo, pieza fundamental y piedra angular en las constantes luchas y en la resistencia contra la ocupación israelí. Al mismo tiempo, intenta siempre mejorar la situación de la mujer palestina de múltiples maneras, empezando por cambiar leyes existentes e imponer otras nuevas menos discriminatorias. En este trabajo se describen los factores que fomentaron la participación socio-política de la mujer, así como los obstáculos que la impidieron y siguen haciéndolo.

Abstract: The aim of this study is to highlight the important role that Palestinian women have played in the social and political life of their country from the beginning of the XX century (even at the end of the XIX century, too) till nowadays. The Feminist Palestinian Movement was, and still is, a fundamental part and a cornerstone in the constant struggle and in the resistance against the Israeli occupation. Concurrently, it always tries to improve the situation of the Palestinian woman in various ways, starting by changing existent laws and imposing others which are new and less discriminatory. This work describes the factors that fostered the socio-political participation of women, as well as the hindrances that prevented them and continue doing so.

Palabras clave: Palestina; Mujer; Sociedad; Movimiento Femenino

Palestine; Women; Society; Feminist Movement 


\section{Introducción}

Las mujeres han sido una parte muy importante en la sociedad palestina a lo largo de la historia, al lado del hombre, que las ha solido apoyar en los últimos tiempos. La mujer desempeñó una papel casi decisivo en la lucha contra la ocupación israelí durante el siglo XX, pues es la que ha mantenido el tejido social de manera coherente. Ella salió en manifestaciones y protestas contra la emigración judía a Palestina el año 1893 y contra el Compromiso de Balfour ${ }^{1}$ el año 1917, también es la que creó las organizaciones de socorro y de caridad social antes de la $\mathrm{Nakba}^{2}$ el año 1948 y promovió el nivel cultural, económico y mental de las mujeres palestinas. Ellas trabajaban en el campo diplomático y mandaron cartas al mundo árabe y occidental para lograr la prohibición de la emigración judía a Palestina y para conseguir su independencia total. Después de la Nakba, el trabajo femenino tuvo un carácter más político y de socorro en los Campos de Refugiados palestinos, dentro y fuera de Palestina, y pertenecieron al Movimiento Nacional de Resistencia contra la ocupación israelí, especialmente después de la $\mathrm{Naksa}^{3}$ del año 1967. En los años setenta y ochenta, y en la Primera Intifada, la participación femenina se hizo más popular, eficaz, orientada, sistemática y amplia a través de Palestina; después de la llegada de la Autoridad Palestina al poder, el trabajo femenino tuvo un carácter de élite y las mujeres del Movimiento Femenino pudieron intervenir en los asuntos relacionados con la mujer palestina a nivel judicial y legal.

En Palestina, la mujer se ha hecho fuerte debido a la crueldad de la ocupación israelí y a la dura vida que ha llevado; todo eso la ha transformado en desafiante, valiente, de mucho coraje y con voluntad para resistir a la ocupación israelí y a los desafíos de la vida y también para convertirla en una persona arraigada firmemente en su tierra; sin duda, la mujer palestina es la más respetada en todo el mundo árabe.

El Movimiento Femenino Palestino ha pasado, a lo largo del siglo XX (y aún antes y en la actualidad), por importantes etapas, que a continuación destacamos.

\section{Primera Etapa: Los inicios de la participación política de la mujer palestina}

La primera acción femenina contra la emigración judía a Palestina tuvo lugar el año 1893, cuando las mujeres salieron en manifestaciones y protestas, y lucharon al lado de los hombres. Los inicios de los años veinte, hasta el fin del Mandato Británico, es conocida como la etapa embrionaria del Movimiento Femenino Palestino; a la vez, se distingue por la falta del registro de las organizaciones femeninas, sus programas, miembros y sus actividades. Durante esta etapa el trabajo femenino tuvo carácter social, como la Organización Ortodoxa del Socoro para los Pobres, pues luchaba para mantener el tejido de la sociedad palestina, pero durante la época del Mandato Británico el trabajo femenino se transformó en trabajo político y armado, pues las mujeres establecieron organizaciones de carácter militar

$1 \mathrm{El}$ compromiso de Balfour fue firmado por el Ministro de Asuntos Exteriores británico, Arthur Balfour, quien prometió, en una carta dirigida al dirigente sionista británico Lord Rochschild, el 22 de noviembre de 1917, apoyar la construcción de un estado judío encima de la tierra de Palestina. Este compromiso estaba claramente en contradicción con la promesa hecha en el mismo periodo a los dirigentes Árabes, que se habían rebelado contra los turcos, a quienes se les prometió otorgarles el gobierno palestino. Tras la Primera Guerra Mundial, Palestina fue asignada a Gran Bretaña como mandato de la Sociedad de Naciones; en adelante, los intentos británicos de reconciliar ambas promesas marcaron el inicio de los problemas en esta zona del mundo.

2 Al-Nakba: así se denomina al momento en el que Israel ocupó las tierras palestinas el año 1948 y anunció el establecimiento del Estado de Israel. En esa fecha los israelíes cometieron matanzas contra el pueblo palestino y expulsó a muchos palestinos de su tierra natal.

3 La Naksa ocurrió cuando, en 1967, Israel ocupó el resto de la tierra histórica palestina (Cisjordania y la Franja de Gaza) después del triunfo que Israel logró en la llamada Guerra de los Seis Días, en junio de ese mismo año. 
puro y organizado para luchar contra el Mandato Británico y contra los diferentes grupos armados judíos en Palestina. La señora Muhiba Khurashid fundó la organización "Zahrat Al- Okhuan"4 en los años treinta y cuarenta, que era una organización femenina secreta que trabajó bajo el marco social femenino y desempeñó un papel inmenso en las diferentes ciudades palestinas, especialmente en Jaffa y en Tel Aviv, en las confrontaciones diarias entre los palestinos, los soldados británicos y los grupos sionistas a través de la resistencia armada, en la colecta de donaciones y transfiriendo armas e importantes noticias e informaciones a los revolucionarios. En estas organizaciones femeninas todas sus miembros vivían en las ciudades, ninguna de ellas en las zonas rurales; sin embargo, a la vez, hubo una gran colaboración entre las mujeres rurales y las mujeres urbanas a la hora de trasladar armas, intercambiar información y formar un cuerpo móvil de alarma para proteger a los revolucionarios, vigilando y controlando las carreteras e, incluso, combatieron contra los soldados británicos para liberar a los revolucionarios palestinos arrestados.

En la revolución del año 1936, en la Gran Huelga, surgió un grupo de mujeres llamado "Las Compañeras del Kassam"5 cuando ellas participaron con el líder de la revolución, EzEddin Al-Kassam ${ }^{6}$, en las luchas contra el Mandato Británico en el campo de batalla. La señora Halima Haj Muhamad, hermana del dirigente de la revolución, se hizo famosa por su participación política y acción militar; sus hermanos la habían entrenado en el uso de las armas y ella disparó contra los soldados británicos.

Es obvio que las mujeres activas política y militarmente pertenecieron a familias cuyos miembros estaban involucrados en la revolución y en las actividades políticas y militares contra el Mandato Británico y los sionistas en Palestina, ya fueran sus padres, maridos o hermanos.

Las mujeres, en Haifa, llevaron a cabo una sentada frente a la cárcel del Gobierno Británico pidiendo que liberaran a los presos políticos palestinos que estaban en huelga de hambre; como consecuencia, el Gobierno Británico fue obligado a recibir a una delegación de las mujeres manifestantes en su despacho y, como resultado, el Alto Comisionado les prometió liberar a cien de los presos políticos y tener en cuenta a los demás. La Dra. Faiha Abdel-Hadi (una activista femenina y profesora de sociología), disertó sobre el papel de la mujer palestina en esta etapa, y dijo ${ }^{7}$ :

"Existe poca mención en la historia escrita sobre la mujer palestina, mientras que la historia oral recuerda el inmenso y eficaz papel de las mujeres palestinas procedentes de las ciudades y se olvidó mencionar el importante papel de las mujeres procedentes de las aldeas y de las zonas rurales. Las mujeres, en esta etapa, sufrieron la tiranía del Mandato Británico y de los sionistas. Por ejemplo: La señora Fatima Ghazal fue martirizada durante una batalla entre los soldados británicos y los revolucionarios palestinos".

Las mujeres han luchado codo con codo al lado de los hombres; existieron algunas que

4 http://zamnpress.com/content/29081. 5-8-2013. Joseph Chaib: "Los cuentos de los inicios desconocidos" (traducción del árabe).

5 https://www.al-akhbar.com/node/157254. 10-11-06. Joseph Chaib: "Crisantemos rojos en la memoria de Palestina" (traducción del árabe).

6 Ez-Eddin Al-Kassam: (1871- 1935) fue un líder sirio que formó células de resistencia contra el Mandato Británico y los grupos sionistas en Palestina en los años veinte. Participó en muchas batallas y confrontaciones con el fin de liberar a Palestina. Murió martirizado, junto con sus compañeros, en el bosque de Ya'bad, cerca de la

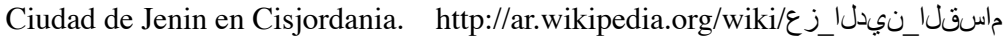

7 Dra. Faiha Abdel-Hadi: "Palestinian Woman and Memory". Workshop Papers about oral wording of her political intervention in the history of palestinian woman. April 1998. Department of Planning and Development of Woman Participation. Ministry of International Planning and Cooperation. Ramallah (Palestine), 2002. 
llevaron armas a los hombres y lucharon con ellos en los túneles, participaron en las protestas y estuvieron en los lugares de las batallas ofreciendo la ayuda médica; como resultado, nueve mujeres fueron asesinadas por los británicos y los sionistas en esta época.

En esta etapa las mujeres tuvieron un profundo conocimiento y una amplia visión sobre la situación política y social que sufrió el pueblo palestino en esos cruciales años. Las mujeres procuraron fortalecer su posición mediante el desarrollo de su estatus en la comunidad académica y científica. Desde el año 1939 hasta 1948, casi 200 organizaciones femeninas fueron creadas por el Movimiento Femenino Palestino. Sus numerosas actividades se concentraron básicamente en prestar los servicios de socorro humano y médico y en las actividades de la resistencia nacional contra las políticas del Mandato Británico y la emigración judía a Palestina. Las mujeres han llevado a cabo importantes actividades durante esta etapa; por ejemplo:

1. Convocaron la primera Conferencia femenina el año 1929 en Jerusalén y otra importante Conferencia internacional en El Cairo (Egipto) en el año 1944 para discutir sobre la situación de la mujer palestina y para crear una caja de financiación que apoyara al pueblo palestino. Además, debatieron sobre la emigración israelí a Palestina y la posesión de las tierras palestinas por los sionistas.

2. Mandaron una carta al el Primer Ministro Británico y a su gobierno para que prohibieran la emigración judía a Palestina y les concedieran su independencia total.

3. Enviaron una carta de protesta al Alto Cargo del Mandato Británico para que soltaran a los políticos palestinos presos en las cárceles británicas.

4. Ilustraron e informaron a la opinión pública palestina sobre la cuestión vigente y enriquecieron el concepto del nacionalismo mediante la convocatoria de seminarios, encuentros y publicaciones a través de la Radio Palestina "Jerusalén Aquí", que atrajo a muchas personalidades femeninas famosas. Por ejemplo: Kudsieh Khurashid, quien presentó el programa "La Personalidad de la Mujer Palestina" el año 1938. Asimismo, la señora Maria Surf realizó el programa "La Educación de la Familia Árabe".

5. Se pronunciaron discursos políticos desde los púlpitos de las mezquitas y en las iglesias para planificar las diferentes actividades políticas como protestas, manifestaciones, sentadas, confrontaciones, etc.

6. Jugaron un gran papel diplomático enviando cartas a los consulados y embajadas extranjeras en Jerusalén, en las que explicaban la situación política existente en aquella etapa; también se reunieron con los embajadores y cónsules para mostrarles los riesgos que amenazaban a Palestina y a su pueblo en aquella etapa.

La mayoría de las mujeres activas en las ciudades pertenecieron a familias muy conocidas e, incluso, famosas, como las señoras Tarab Aldel-Hadi y Mariam Hashem, de Nablus o las señoras Sathej Nassar y Mariam Khalil, de Haifa. El principal papel encomendado a las mujeres de las zonas urbanas se concentró en organizar las diferentes acciones de la resistencia, como las manifestaciones masivas, las protestas y las sentadas; incluso convocaron conferencias a nivel local e internacional; además realizaron un papel diplomático, porque todas tuvieron un buen nivel de enseñanza, puesto que algunas de ellas pudieron llegar a la educación universitaria.

Mientras, la mayoría de las mujeres aldeanas y de zonas rurales eran analfabetas. Por ejemplo: las señoras Fatima Ghazal, de la aldea Azun, en la provincia de Qalquilia o Nabiha Naser, de la Aldea Birzeit, en la provincia de Ramallah. El papel de esas mujeres ha sido de mayor eficacia, pues estuvieron más involucradas en los actos de la revolución, que sin ellas no hubiera podido continuar. Incluso llegaron a vender sus joyas y donaron el dinero para el socorro de los palestinos heridos y para sus familias, muy perjudicadas por la tiranía del Mandato Británico y los sionistas en aquel tiempo. También ellas tuvieron un alto sentido 
patriota, pues se encontraron en el corazón de la revolución que las hizo sufrir tanto como a los hombres. Por ejemplo: fueron arrestadas por el Gobierno Británico por poseer rifles y esconderlos con otros tipos de armas, además fueron encarceladas en las cárceles británicas. La señora Fatima Shaskieh luchó al lado de su marido, participó en la mayoría de las actividades de la resistencia patriota y fue conocida por su hábil uso de diferentes armas.

En los años treinta y cuarenta, la mujer palestina ha disfrutado de un digno estatus en lo relacionado con lo político, a pesar de tener una posición social menor debido al poder de las tradiciones y costumbres; sin embargo, y pese a ello, debemos de reconocer que tuvo un mayor reconocimiento social que el del resto de la mujer en el mundo árabe. La lucha patriota del pueblo palestino en su conjunto produjo cambios en los valores y costumbres sociales; la participación de la mujer en la arena política, su lucha patriota de manera eficaz y en la práctica real le hizo ganar gran prestigio y respeto social, a pesar de las limitaciones sociales, porque las condiciones de lucha han impuesto la aceptación social a los movimientos de las mujeres activas políticamente. Por ejemplo: salir de casa en cualquier momento sin tener que explicar la razón de su salida; luego las mujeres empezaron rechazar el Neqab de la cara y lo fueron abandonando, hasta conseguir dejar el velo totalmente en los años cuarenta.

Segunda Etapa: El Movimiento Femenino Palestino durante la guerra del año 1948

En el año 1948 el Mandato Británico entregó la tierra histórica de Palestina a los sionistas judíos quienes, de inmediato, anunciaron la creación del Estado de Israel. Los israelíes $\mathrm{y}$, en especial, los sionistas atacaron al pueblo palestino en las ciudades y en las aldeas, destruyendo muchas de ellas totalmente y cometieron numerosas matanzas contra los palestinos; muchos de ellos tuvieron que refugiarse en las zonas interiores de Palestina y en los países árabes vecinos, hecho que causó un gran desgarro en el tejido social y nacional palestino. Como consecuencia, cambió el carácter del trabajo de las organizaciones femeninas, que se concentró más intensivamente en el socorro sanitario y médico durante la guerra y pocos años después. El trabajo femenino se amplió más y de forma sistemática porque el Movimiento Femenino Palestino inauguró nuevas organizaciones para prestar servicios de socorro en Jaffa y en otras ciudades palestinas, proporcionando a los revolucionarios armas, medicinas y comida. Además, se formaron comisiones femeninas para socorrer a los heridos en el campo de batalla, e incluso fundaron nuevos hospitales y clínicas sanitarias para prestar servicios médicos al pueblo palestino durante la guerra.

Los palestinos vivieron todos estos acontecimientos en tres ambientes diferentes: en la ciudad, en las aldeas y en los recién creados o ampliados campos de refugiados. En esta etapa, la nueva situación ha puesto de relieve la posición de la mujer palestina en la sociedad; su papel aumentó y se valoró adecuadamente, por ello su personalidad creció, realizándose un cambio muy positivo en la consideración de la sociedad hacia la mujer. Las mujeres tuvieron que hacer frente a nuevos cargos y problemas adicionales, especialmente cuando su tutor estaba ausente (ya estuviera muerto o hubiera caído como mártir o preso político); en esos casos la mujer tenía que afrontar la nueva dura vida, la pobreza, la orfandad, pertenecer a los sin techo, etc.; además la mujer se vio obligada a salir a trabajar, lo que influyó en que participara en las actividades de los partidos políticos mucho más que antes.

Durante esta etapa, desde el año 1948, Jordania empezó a gobernar al pueblo palestino en la zona de Cisjordania; mientras que Egipto gobernaba en La Franja de Gaza. Bajo el nuevo Gobierno jordano, y después de la Nakba, las organizaciones y los institutos femeninos fueron activados y su número creció mucho, para proporcionar el auxilio social y para aliviar los efectos de la Nakba entre el pueblo palestino. Se formó la base femenina que le ofreció el apoyo financiero y psicológico. Aunque, a la vez, existieron opiniones opuestas que afirman que el Movimiento Femenino Palestino, durante esta etapa, estuvo marginado y carente de desarrollo sustancial, tanto en lo social como en lo político; ocurrió una rup- 
tura mayor en el trabajo femenino debido a que las mujeres no formaron un movimiento de carácter patriota y social. En estos años se produjo una contradicción sobre el Movimiento Femenino Palestino, por lo que prosigue una ambigüedad en lo concerniente a la naturaleza del trabajo femenino durante aquel tiempo.

Cuando se creó la Organización de Liberación de Palestina ${ }^{8}$ (OLP), en el año 1964, invitó a la mujer palestina y a las diferentes organizaciones femeninas (estuvieran dentro o fuera de Palestina) para que participaran y se unieran a la OLP. Esta organización dio un gran empujón al feminismo palestino. Las mujeres líderes del Movimiento Femenino participaron en la primera conferencia de la OLP, y formaron la Unión General de la Mujer Palestina. Desde ese momento las actividades del Movimiento Femenino se concentraron más en el trabajo político sistemático. Ahmad Al-Shukairi, Presidente de la OLP, afirmó: "La OLP ha cumplido su compromiso con su otra mitad (las mujeres)".

En la guerra de los Seis Días del año 1967, Israel ocupó el resto de la tierra histórica de Palestina (Cisjordania y la Franja de Gaza). Durante los diez años siguientes a 1967, el número de las organizaciones se duplicó y la mayoría de ellas se crearon en las grandes ciudades como Jerusalén, que ha concentrado a más de la mitad de estas organizaciones femeninas; pero más organizaciones nuevas empezaron a aparecer en los pueblos y menos en los campos de refugiados, porque la $\mathrm{UNRWA}^{9}$ se hizo responsable de los refugiados palestinos y lo sigue siendo hasta ahora. Las mujeres intensificaron su trabajo durante esta etapa, que se amplificó y diversificó en un intento de satisfacer todas las necesidades del pueblo palestino, remediando muchos sufrimientos que padecía bajo la ocupación israelí. El trabajo en las organizaciones femeninas se concentró en lo siguiente:

- Actividades femeninas sociales que se diferenciaban del trabajo de las organizaciones de caridad.

- Convocaron cursos para eliminar el analfabetismo, tanto para los hombres como para las mujeres.

- También convocaron cursos de rehabilitación profesional para las mujeres (de costura, de estética, de enseñanza, de hilatura, de tricotar, etc.), para que pudieran afrontar la nueva y dura situación humana y económica, y para empujarlas a buscar un trabajo con el que ayudaran a sus familias.

- Se crearon jardines de infancia porque a la sociedad palestina les faltaba durante la ocupación israelí.

- Fundaron clínicas sanitarias y hospitales para cuidar la salud del pueblo palestino.

- Crearon granjas y huertos para animar a la clase agraria, especialmente a mediados de los años ochenta, con la colaboración entre las mujeres unidas en los pueblos para que produjeran productos que les proporcionaran rentas económicas que les permitieran mantenerse, no sólo ella, sino incluso a sus familias.

- Realizaron actividades de diversión y de entretenimiento, especialmente para los

8 La Organización para la Liberación de Palestina (OLP) fue creada en 1964 en El Cairo (Egipto), auspiciada por el presidente Gamal Abdel Naser. Su objetivo era luchar contra la ocupación de Israel y su tiranía contra la población de Palestina ateniéndose a la legitimidad internacional; además, pretendía devolver a los refugiados palestinos a su tierra de la que los israelíes los fueron exiliando después de la Guerra de 1948 y tras la Guerra de los Seis Días, en el año 1967.

9 Siglas de "United Nations Relief and Works Agency for Palestine Refugees in the Near East" (Organización de las Naciones Unidas para la ayuda a los refugiados palestinos en el Próximo Oriente).Este organismo fue creado mediante la resolución 302 de la Asambla General de la ONU, en el año 1948, cuando los judíos cometieron masacres contra el pueblo palestino y, después, establecieron el Estado de Israel en la tierra histórica de Palestina. El objetivo de esta Organización era proporcionar ayuda directa y trabajo a los refugiados palestinos, con el fin de evitar situaciones de hambre y de angustia, y para intentar crear condiciones de paz y de estabilidad entre las personas que habían sido expulsadas de su tierra natal. 
jóvenes, abriendo clubes sociales. También se dieron clases de cultura y de religión y se hicieron campamentos estudiantiles.

- Convocaron las conferencias femeninas para estudiar los diferentes asuntos políticos y patriotas.

- Actividades políticas: asistir y ayudar a los presos en las cárceles israelíes y a sus familias, procurando aliviar su sufrimiento diario, apoyándoles, además de pedir a los israelíes que los soltaran.

Defendieron los lugares y los sitios sagrados (musulmanes y cristianos) en Palestina, convocando protestas pacíficas en la explanada de la mezquita de Al Aqsa en Jerusalén, por confirmar que dicha mezquita es palestina y árabe totalmente, condenando el permiso israelí a los extremistas israelíes para que pudieran rezar en esa explanada sagrada y, menos, en sus mezquitas.

- Participaron en las manifestaciones contra los asentamientos y las colonias israelíes en Palestina, contra la confiscación de las tierras palestinas y contra la atrocidad israelí y sus procedimientos brutales contra el pueblo palestino en general.

Las mujeres palestinas han desempeñado un papel muy importante intentando mantener el tejido social palestino fuerte e inquebrantable lo más posible; así ayudaron mucho a la conservación de la Identidad Nacional Palestina.

Durante los años setenta y ochenta, empezó la formación de los partidos políticos palestinos; concentraron su trabajo en la resistencia patriota contra la ocupación israelí, y las mujeres comenzaron a afiliarse a dichos partidos políticos, aunque su número fue mucho menor que el de los hombres, especialmente para el trabajo militar; como resultado, cada partido político empezó a formar su propia liga femenina el año 1978, para promover la situación de la mujer en todos los segmentos de la sociedad o en todos los campos, sin tener en cuenta su ideología política o su religión. Además, reforzaron al pueblo palestino en los territorios ocupados mediante el trabajo femenino orientado y planificado; las mujeres llevaron a cabo los programas patriotas que eran una mezcla entre las tareas nacionales, políticas y las tareas tradicionales sociales femeninas. El número de las mujeres y chicas miembros de esas ligas fue superior a 8.000.

Las alumnas tuvieron un papel político crucial en el trabajo sindical en las universidades palestinas; ellas se involucraron en los Consejos Estudiantiles desde el curso 1986/1987 y participaron en el proceso de toma de decisiones en lo relacionado al trabajo político patriota. Además, los partidos políticos se han dirigido a las alumnas universitarias para formarlas políticamente y difundir la conciencia sobre el trabajo político y militar entre ellas. En esta etapa, el Movimiento Femenino Palestino fue muy activo y siempre apoyado por la OLP, los partidos políticos, las ligas femeninas y el Movimiento Estudiantil Nacional en las universidades palestinas. El trabajo femenino siguió el mismo ritmo hasta el inicio de la Primera Intifada.

\section{Tercera Etapa: La Primera Intifada}

La Primera Intifada empezó a finales del año 1987 y continuó durante seis años, cuando se firmó el Proceso de Paz (Los Acuerdos de Oslo ${ }^{10}$ ) que tuvo lugar el año 1993 y, también, cuando en el mismo año se creó la Autoridad Nacional Palestina (ANP) ${ }^{11}$. En esta etapa

10 Los Acuerdos de Oslo: fueron una serie de acuerdos negociados entre el Gobierno Israelí y la OLP que actuó como represente de Palestina. Esos acuerdos fueron firmadas en el año 1993 en la ciudad de Oslo, la capital de Noruega, como una parte del proceso de la paz entre la OLP e Israel; oficialmente es llamada la Declaración de los Principios.

11 La ANP es una Organización administrativa con autonomía que gobierna transitoriamente, desde el año 1994, en la Franja de Gaza y en partes de Cisjordania, creada según los Acuerdos de Oslo. Posteriormente, el 
las mujeres del Movimiento Femenino Palestino fueron muy activas, eficaces, con poder y valientes durante la Intifada; participaron, de una manera sistemática, en las diversas actividades de esa Intifada y se distinguieron en las intensas y diarias confrontaciones con el Ejército Israelí, en las protestas y sentadas en las que reclamaban la libertad para Palestina y la liberación del pueblo palestino de la ocupación israelí.

Durante esta etapa, el Movimiento Femenino Palestino Laico (MFPL) creció considerablemente, horizontal y verticalmente; miles de mujeres estuvieron involucradas en el trabajo político y social, por lo que su papel aumentó y se convirtió en necesario para apoyar a la resistencia patriota, proporcionándoles comida, medicinas, armas, piedras, etc.; es decir, el auxilio primario necesario en los campos de batallas, arriesgándose al llevar debajo de su ropa los folletos sobre las manifestaciones y actividades de la Intifada realizados por el liderazgo unificado de la Intifada para distribuirlos en toda Palestina. La base de las ligas femeninas se hizo muy amplia y popular; a ella pertenecían mujeres de diferentes edades, de todos los ambientes y sectores sociales de la comunidad palestina; musulmanas, cristianas y samaritanas han trabajado juntas y afrontaron las mismas circunstancias de la Intifada, sufriendo las mismas consecuencias por su participación política en ella. Las ligas femeninas han organizado casi todas las actividades de la Intifada, aunque no nos podemos olvidar de la participación espontánea de las mujeres independientes políticamente. Durante la Intifada, las mujeres han roto las cadenas de las tradiciones y costumbres, pues actuaron con los hombres en la participación política y militar; los hombres se acostumbraron a la presencia de las mujeres a su lado en la batalla de liberación. Muchas mujeres fueron arrestadas, heridas, humilladas, martirizadas, insultadas y atacadas físicamente por el ejército israelí mientras formaban un escudo y un amparo para proteger a los hombres, evitando que fueran arrestados o matados por los soldados israelíes. La mayoría de las mujeres pertenecieron a Fateh, otras a los partidos izquierdistas, pues el Movimiento Femenino Islamista no surgió en Palestina hasta los inicios de los años noventa. Las actividades más destacadas de este Movimiento Femenino, durante la Primera Intifada, son:

1. Acoger a los grupos extranjeros simpatizantes con el pueblo palestino con hospitalidad y explicarles la actual situación en la Intifada.

2. Formar parte del Liderazgo Unificado de la Intifada a nivel nacional. Además, participar en el proceso de toma de decisiones en lo relacionado con las manifestaciones y actividades de la Intifada.

3. Organizar visitas incesantes a las familias de los presos, heridos y mártires durante de la Intifada, apoyándoles moral y económicamente.

4. Inaugurar jardines de infancia y clínicas sanitarias para servir a la comunidad local; a la vez, movilizar a las mujeres políticamente.

5. Convocar encuentros culturales para difundir la conciencia política, sanitaria, patriota y científica entre las mujeres.

6. Formar comités de educación popular en los barrios de las aldeas, las ciudades y los campos de refugiados; establecer escuelas populares, donde las mujeres son las encargadas de esta gran tarea porque su accesibilidad a los barrios y a las casas les es más fácil que a los hombres. Las mujeres enseñaron los currícula escolares y salvaron el año académico 1988, cuando las autoridades israelíes cerraron las escuelas y las universidades en Palestina durante más de seis meses consecutivos; se concentraron en los niños y niñas de la primera etapa escolar, después el trabajo se desarrolló y se abrieron escuelas en los barrio o en las casas de las mujeres de las ligas femeninas.

29 de noviembre de 2012, mediante la Resolución 67/19, la Asamblea General de la ONU pasó a considerar a Palestina como "Estado" frente a la interior consideración de "Entidad". En enero 2013 adoptó oficialmente el nombre de Estado de Palestina 
7. Crear jardines y huertos en las casas para plantar verduras, frutas y hierbas comestibles con el fin de conseguir la autosuficiencia alimentaria y económica de las familias.

8. Coordinadas con la Cruz Roja Internacional, proporcionaron medicinas, equipamiento y materiales médicos, comida a los barrios, aldeas y campos de refugiados.

\section{Cuarta Etapa: Desde la llegada de la Autoridad Nacional Palestina al poder hasta el año 2005}

Después de constituirse el gobierno de la Autoridad Nacional Palestina (ANP), ocurrió un cambio en los mecanismos y estilos de la lucha del Movimiento Femenino Laico (MFPL) contra la ocupación israelí. Con el establecimiento de la ANP, se crearon nuevas instituciones del Estado Palestino, como los diferentes Ministerios dedicados a diversos asuntos específicos, que empezaron a reanudar el trabajo y a prestar los servicios que las ligas femeninas realizaban durante la Primera Intifada y los años setenta a favor de la comunidad palestina.

El movimiento femenino laico se enfrentó a un duro golpe cuando los Acuerdos de Oslo, porque se produjo una gran confusión sobre el proyecto nacional. Sus miembros se dividieron entre apoyar o no apoyar dichos acuerdos, porque cada grupo siguió la posición de su partido político.

Cuando se terminó la confusión, las mujeres se ocuparon de desarrollar un conjunto de principios, objetivos y controles desde un punto de vista femenino, en un intento de conservar los logros del MFPL que ellas habían llevado a cabo en los años setenta y ochenta, temiendo que la ANP y la corriente política prevaleciente las dejara atrás. El MFPL quería lograr una base sólida en el sector gubernamental y privado. La ANP estabilizó las Unidades de Género en la mayoría de los Ministerios palestinos, pero no resultaron útiles para las mujeres por razones técnicas. Ellas habían creado las ONGs y las instituciones femeninas para movilizar y activar a las mujeres, trabajando para mejorar su situación y promover el estatus de las mujeres en general. Las líderes del MFPL dejaron sus puestos y sus importantes papeles y se dirigieron al trabajo gubernamental. Además, se produjo una ausencia de los comités del trabajo social y de las ligas femeninas, porque el MFPL se había fusionado totalmente con las instituciones gubernamentales. Dejaron el trabajo popular de masas e ignoraron trabajar con la base femenina, y así se perdieron todos los logros que las mujeres llevaron a cabo durante los años setenta y ochenta.

Las mujeres desconocían el modo de actuar en el trabajo gubernamental e institucional; por eso las del MFPL, sobre todo, reflexionaron y empezaron a buscar empleo en las instituciones de la ANP donde los puestos de trabajo eran limitados; como resultado, la mayoría de las instituciones femeninas creadas durante los años precedentes cerraron sus puertas y las ligas femeninas perdieron su amplia base de mujeres y su apoyo político e, incluso, algunas marcharon al sector privado.

El Ministerio de Asuntos de la Mujer y el MFPL se integraron, de manera oficial, en el plan de trabajo y en la estrategia del Gobierno Palestino en el año 1999, cuando se establecieron las competencias de cada Ministerio; así las mujeres dieron el primer paso del camino para poder trabajar de manera correcta y sistemática. Por ejemplo: desarrollar la estrategia intersectorial, que es la actual, la cual establece todo lo que se necesita de cada Ministerio a favor de las mujeres. Plantearon las prioridades, ejes y objetivos, y el MFPL ha empezado a aplicarlos todos. Actualmente se efectúa una evaluación y una revisión de la estrategia que las mujeres pudieron, o no, llevar a cabo hasta ahora, para crear una nueva que se extienda a los años 2014-2016 y así cerrar las fisuras de los años pasados en el trabajo femenino. Establecieron la Estrategia Nacional para Combatir la Violencia contra la Mujer Palestina y firmaron un memorando de entendimiento el año 2011 con el fin de involucrar a un grupo de mujeres en la defensa civil. También diseñaron un presupuesto sensibilizado 
con las diferencias de género y, en concreto, con las que sufrían las mujeres; consiguieron lograr la aprobación del gobierno palestino y formaron un equipo de mujeres para seguir la praxis de dicho presupuesto. Este equipo nacional reúne miembros de diversas instituciones civiles y gubernamentales para aprobar y aplicar la resolución $1325^{12}$ en Palestina. Crearon el mecanismo de auditoría de género en el Ministerio de Trabajo, en la Unión de los Sindicatos de los Trabajadores Palestinos y en las Cámaras del Comercio Industrial y Agrícola. También lograron que su Estrategia Nacional de Género se involucrara en el sector del medio ambiente, las aguas y los residuos sólidos, aprobadas por el Consejo de Ministros. Constituyeron las Unidades de Género en la mayoría de los Ministerios Palestinos. Aprobaron la Ley de la Protección de la Familia y contra la Violencia, mediante la expedición de un decreto presidencial. Asistieron a la Conferencia anual de la ONU sobre la mujer, se esforzaron para adherirse a la Convención de $\mathrm{CEDAW}^{13}$ y a otras convenciones internacionales a favor de la mujer. El trabajo femenino actual tiene carácter institucional, es un trabajo de élite, y está vinculado a los proyectos y a la financiación de los donantes extranjeros, los cuales, muchas veces, especifican las estrategias de las organizaciones e instituciones femeninas; los temas del trabajo normalmente están impuestos por los países donantes, aunque no es un trabajo completo porque se concentra en una clase de mujeres y se olvidaron de trabajar con las mujeres marginadas y desfavorecidas, que forman una amplia base en esta situación económica drástica y dramática. A pesar del apoyo de la ANP a la mujer palestina y a la creación de un Ministerio por ellas, las Unidades de Género todavía no logran mejorar mucho la situación de la mujer palestina debido a la mente patriarcal y machista que domina las esferas del trabajo. La ANP aún concede la prioridad al trabajo político y a satisfacer las necesidades del pueblo palestino, y considera los asuntos sociales como secundarios, aplazándolos hasta después de la liberación de Palestina. A nivel político, las mujeres están excluidas de las mesas de negociaciones con el Estado israelí, al igual que lo fueron de las negociaciones de reconciliación entre Fateh y Hamas.

El Presidente de Palestina, Yaser Arafat, estaba interesado en involucrar a las mujeres en las instituciones de la ANP y en los puestos de toma de decisiones, por lo que nombró ministras, embajadoras, diputadas y miembros en los Consejos Locales y Municipales. Las mujeres palestinas participaron en el proceso electoral como votantes y como candidatas para el Consejo Legislativo Palestino del año 1996; cinco mujeres tuvieron éxito y participaron en el proceso legislativo y de reconstrucción del nuevo Estado Palestino. Las leyes existentes en Cisjordania antes de la llegada de la ANP al poder, eran leyes jordanas y el Islam era la fuente principal de las legislaciones. Pero el MFPL quería trasladar las necesidades de las mujeres palestinas a los marcos jurídicos legislativos, así como formular proyectos de leyes para lograr la justicia, libertad, igualdad y el desarrollo social sostenible en Palestina. El año 1994 las mujeres pudieron imponer el sistema de cuota femenina, con un porcentaje del 20\%, en la Ley de las Elecciones Legislativas y la Ley de los Consejos Locales y Municipales; en el año 2007 las mujeres consiguieron imponer el sistema electoral de representación proporcional (las listas electorales) y anular totalmente el sistema de departamentos múltiples. En el año 1996 las mujeres formaron el Parlamento el Sury ${ }^{14}$,

12 La Resolución 1325 - sobre mujer, paz y seguridad - presenta una serie de recomendaciones a todos los actores implicados en los conflictos armados y, de manera particular, a los países, principalmente sobre la protección de las mujeres y las niñas para incorporarlas en las mesas de negociación de la paz. Esta resolución se convierte en el primer instrumento del Sistema que reconoce los efectos de los conflictos armados sobre la vida de las mujeres y el papel de éstas en la prevención de los conflictos y como promotoras de paz.

13 Ésta es una Convención sobre la eliminación de todas las formas de discriminación contra la mujer, adaptada y abierta a la firma y ratificación, o adhesión, por la Asamblea General de la ONU en su resolución 34/180, de 18 de diciembre de 1979, que entró en vigor el 3 de septiembre de 1981.

14 Es un Parlamento que las mujeres palestinas formaron después de una campaña nacional para conseguir aprobar legislaciones y leyes que garantizaran la igualdad y los derechos de las mujeres y para deliberar, con 
intentando legislar una nueva Ley de Estatus Personal que sustituyera a la existente ley jordana del año 1960, porque esta injusta para las mujeres. Sugirieron un borrador que representaba el punto de vista femenino, pero se encontró con una fuerte ola de protesta de la corriente islámica y conservadora en Palestina, y todavía debe hallarse en algún cajón del despacho del Presidente Palestino, desde hace cinco años. Además, las mujeres propusieron cambiar la Ley del Código Penal, pero también encontraron el mismo rechazo; sin embargo, ellas pudieron ejercer presiones sobre el Presidente Palestino, Mahmoud Abbas, para que expidiera Decretos que cambiaran los artículos 340 y 98, relacionados con el asesinato por honor, para proteger la vida y los derechos de la mujer palestina. También las mujeres, con la coordinación del Juez Supremo de Palestina, Yusef Edeís, lograron cambiar y aprobar los siguientes asuntos a favor de la mujer:

- El Takharoj ${ }^{15}$ : se prohibe antes de seis meses de la fecha de la muerte del padre.

- El Kholo’a: una ley adoptada por la Corte Religiosa que permite a la novia solicitar el divorcio de su novio sólo durante el periodo del noviazgo.

- Expedir una circular para establecer el Fondo de Pensiones Alimenticias en las Cortes Religiosas para proteger a las mujeres divorciadas y a sus hijos.

- Expedir un decreto que obliga al marido a informar a su primera esposa sobre su segundo matrimonio. Además, prohibir el matrimonio secreto.

- Inaugurar tres "Casas Seguras", como refugio seguro para las mujeres maltratadas o amenazadas.

- Trabajar con la Corte Religiosa y poder aumentar la edad del matrimonio desde los 15 años a los 18 para ambos sexos, con algunas excepciones.

El trabajo femenino islámico empezó en la Franja de Gaza, en la mezquita de Dar AlArqam, lugar en el que se destina una esquina para impartir lecciones de religión islámica a las mujeres; después el fenómeno se extendió a Cisjordania.

El inicio del trabajo femenino Islámico institucionalizado apareció como resultado de dos cumbres femeninas en la Universidad de Birzeit (cerca de Ramallah) en los años 1994 y 1995, organizadas por las jóvenes del Movimiento Islamista en la universidad. Muchas organizaciones femeninas islámicas se inauguraron, como El Huda en la ciudad de Al Bireh, en el año 1996. En esta etapa esas instituciones fueron registradas oficialmente por la Autoridad Palestina, además se crearon las bases del trabajo con la sociedad local legalmente.

Hamas podría entrar en cada casa palestina, a través de las mujeres, para formar las comisiones en las calles y en los barrios, y para garantizar que el pensamiento femenino islámico llegara a todos los lugares. El movimiento islamista masculino empezó a valorar los beneficios políticos que se podían lograr con el trabajo de las mujeres, hasta formar un movimiento femenino islamista popular de base. Hamas pensó que se podía extender más gracias a la actividad femenina. El Movimiento Femenino Islámico (MFPI) fue creado básicamente desde la realidad social, para que trabajara con las masas populares, con las mujeres de la base, las mujeres más desfavorecidas de la sociedad; y se extendió para ofrecer sus diferentes servicios a los pobres y a los marginados, prestando servicios educativos y de sanidad en las zonas alejadas y aisladas. Además, ofertan servicios alternativos de alta calidad a precios bajos a la gente, como los sanitarios; también solucionan los problemas de las mujeres, dan dinero de la limosna a los pobres, a los huérfanos y a las familias de los mártires, los presos y a los heridos de la Intifada. Incluso ofrecen cursos de formación aca-

opiniones libres, sobre los asuntos de las mujeres y mejorar su situación en Palestina.

15 Es la petición del inventario de la herencia del padre muerto. Dicho inventario se encuentra en un documento expedido por la Corte Religiosa donde figura el número de los herederos e indica la proporción correspondiente a cada uno de ellos. 
démica para las chicas y las mujeres pobres en diferentes temas: artesanía, informática, secretariado, enfermería, etc. También establecieron jardines infantiles y proyectos para crear trabajo y oportunidades para las mujeres. Pretendieron mejorar la situación económica de la mujer mediante la creación de oportunidades de trabajo tradicional, para que luego pudieran vender esos productos. Además, el Movimiento Islámico de las alumnas en las universidades palestinas constituye una parte vital en el trabajo islámico femenino. Dentro de estos movimientos estudiantiles las alumnas llevaron a cabo el trabajo sindical y enseñaron el Islam. Incluso lograron la extensión del modo de vestir islámico, y captaron a muchas chicas para participar en las actividades del movimiento femenino islámico en los años 1994-2005. En esa época los esfuerzos femeninos islámicos crecieron mucho, tanto en eficacia como en actividad. Todo esto ayudó a los movimientos femeninos islamistas para que se extendieran y crecieran rápidamente junto a Hamas y a los partidos políticos islámicos.

Hamas interrumpió las primeras elecciones legislativas y presidenciales del año 1996; como resultado, el Movimiento Femenino Islámico también interrumpió las elecciones y rechazaron participar como candidatas o electoras; se consideró esta interrupción como una protesta contra los Acuerdos de Oslo. Además, rechazaron el sistema de cuota femenina. Sin embargo, Hamas sí participó en las elecciones legislativas del año 2006, y dirigió una llamada al Movimiento Femenino Islámico para que también participara en esas elecciones como candidatas y como electoras. Y Hamas ganó las elecciones legislativas, obteniendo 76 escaños del total de 132 escaños (diecisiete mujeres ganaron las elecciones legislativas, seis de ellas pertenecientes a Hamas). Como consecuencia, Hamas formó el gobierno y nombró a los ministros, presididos por el presidente de Hamas en Palestina, Ismael Hanieh. Éste eligió a la Dra. Mariam Saleh para el Ministerio de los Asuntos de la Mujer. En el siguiente gobierno, también presidido por Ismael Hanieh, hubo dos mujeres, la Ministra de los Asuntos de la Mujer y la Ministra de Turismo y Antigüedades, las cuales no pertenecían a Hamas; sin embargo, estos gobiernos de Hamas no fueron reconocidos y aceptados por el mundo occidental ni tampoco por el árabe. Posteriormente Hamas realizó un golpe de estado en la Franja de Gaza, y constituyó su propio gobierno, nombrando a la señora Jamila Al- Shanti como Ministra de los Asuntos de la Mujer. Sin la menor duda, las mujeres del MFPI fueron decisivas en el triunfo de Hamas en las elecciones legislativas.

El trabajo femenino islámico y laico experimentó una etapa de recesión en los años 2001-2002, durante la invasión militar de Israel a toda Cisjordania. Los judíos irrumpieron en las instituciones gubernamentales y civiles en Cisjordania, rompieron las propiedades, robaron los archivos y ordenadores, y así destruyeron todos los esfuerzos y los logros conseguidos por el MFPL y el MFPI. El año 2003 empezó el periodo de recuperación del trabajo femenino y continuaron con la agenda de trabajo. Durante esta etapa aumentó el sentido religioso y conservador en Palestina, pues los palestinos creyeron que el Islam político era la única solución de la cuestión palestina y desconfiaron de la ley civil. Eso causó un retraso en el MFPL y un apoyo al MFPI, y no existió ningún tipo de coordinación ni de cooperación entre ambos movimientos femeninos. A todo eso se añade que el triunfo de Hamas en las elecciones de 2006 añadió otro retraso en el MFPL.

\section{Quinta Etapa: El Golpe de Estado de Hamas en la Franja de Gaza}

El Golpe de Estado de Hamas en la Franja de Gaza, en junio de 2006, ocurrió porque existía una gran diferencia política y distancia geográfica entre Cisjordania y la Franja de Gaza. Fateh cerró las instituciones de Hamas en Cisjordania y prohibió sus actividades políticas y las femeninas; lo mismo hizo Hamas en Gaza con Fateh, lo que causó disidencia, interrupción y recesión en el trabajo femenino laico e islámico. Hamas y Fateh participaron en las Elecciones de Consejos Locales y Municipales del año 2004-2005, en las que Fateh ganó, consiguiendo 1403 escaños, mientras que Hamas obtuvo 825. De todos 
ellos, 530 fueron mujeres de Fateh y Hamas frente a 1.698 hombres. Las mujeres miembros de los consejos locales y municipales llevaron a cabo programas de trabajos activos y eficaces, desarrollaron la infraestructura en sus ciudades, realizaron trabajos de carácter social, se presentaron servicios y proyectos que afectan directamente a la sociedad local; el único objetivo de las mujeres era promover la situación de la mujer en especial. Hamas se abstuvo de participar en las elecciones de consejos locales y municipales que tuvieron lugar en Cisjordania el año 2012. En general, y según los resultados de las elecciones a los consejos locales, resulta evidente que el papel de la mujer era débil, pues las mujeres fueron obligadas a dimitir inmediatamente después de las elecciones; fueron expulsadas de los consejos, a pesar de su victoria, que a veces fue absoluta. Se las marginó del proceso de toma de decisiones, pues convocaban las reuniones durante la noche (conscientes de la dificultad que las mujeres tenían de salir a esas horas) y prácticamente a escondidas. Incluso asignaron comités específicos para las mujeres, que normalmente eran los tradicionalmente femeninos, como el comité de trabajo social y el sanitario. Además de todos esos obstáculos puestos por los hombres, hay que reconocer que algunas mujeres no estaban cualificadas suficientemente para ocupar su puesto, pues no sabían cómo trabajar, ni se las había preparado e, incluso, ellas no se habían preocupado de hacerlo; sin embargo, a pesar de esa realidad, existen ejemplos de mujeres que lograron grandes éxitos como miembros y presidentas de los consejos locales y municipales.

En el año 2007, y posteriormente, el trabajo del MFPI ha sido prohibido por completo en Cisjordania por la ANP, mientras que el MFPL prosiguió con su trabajo y sus programas, que frecuentemente dependen de los proyectos de trabajo financiados por los diversos países extranjeros. En muchas ocasiones los países donantes imponen su agenda de trabajo como una condición para proporcionar su apoyo económico. El enfoque de esos proyectos está concentrado, desde hace muchos años, en la salud reproductiva, en el dar poder a la mujer, en los derechos de la mujer, etc. Sin embargo, en la realidad, la situación de la mujer no ha mejorado mucho, pues cada organización femenina trabaja sola; cada grupo del MFPL tiene su propio programa de trabajo que diferencia a uno del otro, sin que tengan un objetivo más amplio ni una agenda unificada. Las organizaciones femeninas convocan talleres sobre los asuntos de la mujer palestina, pero no los continúan; se paran y se dejan los papeles de sus proyectos en los cajones y, después, se olvidan. Además, la sociedad patriarcal contribuye a que se limite el impacto positivo del trabajo femenino sobre las mujeres. También hay que reconocer que los proyectos llevados a cabo por el Movimiento Femenino Laico no fueron más que una tapadera para su partido político y para sus propios objetivos. En general, los proyectos no proporcionan los servicios necesarios para las mujeres de base y no sirven para solucionar las necesidades básicas e imprescindibles de las mujeres pobres y desfavorecidas. Normalmente, las mujeres beneficiadas por los talleres son mujeres formadas que no los necesitan. Se ha ido creando un tipo de defecto en la sociedad porque se da poder y trabajan sólo con las mujeres y se olvidan de trabajar con los hombres, los cuales no responden a los programas de las organizaciones femeninas y siguen rechazando cambiar su mentalidad masculina y machista.

\section{Conclusiones}

El Movimiento Femenino Palestino Laico desempeñó un papel muy importante ayudando a cohesionar al pueblo palestino, además de aliviar su sufrimiento diario, especialmente durante las Intifadas y en las diversas crisis políticas. Participó ofreciendo servicios de carácter social y también en el trabajo patriota de muy diversos tipos, desde el inicio del siglo XX hasta la llegada de la ANP al poder. Esas mujeres formaron comités y ligas femeninas que llevaron a cabo un trabajo muy diversificado, pues ha sido un movimiento con una visión clara y un objetivo unificado. Pero después del acceso de la ANP al poder, el 
MFPL empezó a declinar, mientras que el MFPI comenzó a crecer un poco. Sin embargo, después del año 2006 y del Golpe de Estado de Hamas en la Franja de Gaza, el MFPI prácticamente se paralizó por completo, por razones políticas. Mientras, el MFPL siguió con su trabajo a favor de la mujer, a duras penas, convirtiéndose en casi un "semi- movimiento", por las siguientes razones:

- No existe un movimiento femenino puro y decidido, sino que se vislumbran algunos componentes de un tipo de movimiento femenino en las organizaciones femeninas que carecen de un programa unificado y de una visión compartida; también les falta un objetivo más ambicioso y amplio. Las mujeres líderes fueron absorbidas totalmente por el trabajo institucional en la ANP y dejaron sus puestos vacíos; se olvidaron de trabajar con las mujeres de base y perdieron los grandes logros que ellas llevaron a cabo en el siglo pasado. La mayoría de las instituciones femeninas cerraron sus puertas por la ausencia de financiación y de la ayuda de la propia administración; eso afectó negativamente a la segunda y tercera generación de las mujeres y, como resultado, el MFPL perdió su impulso creador y se convirtió en un movimiento de élite. También el trabajo femenino ha sido limitado y controlado por la agenda de los países donantes, y las mujeres de base no se beneficiaron nada de estos proyectos, pues prácticamente han sido excluidas. Por eso la situación económica de las mujeres empezó a empeorar gradualmente, al ser olvidadas y marginadas de las agendas del trabajo femenino actual. El MFPL ya no trabaja en la implementación del desarrollo sostenible en la sociedad.

- La mirada estereotipada de la sociedad palestina hacia el trabajo femenino, especialmente el trabajo laico, constituye el principal obstáculo para el desarrollo del trabajo femenino en Palestina. El MFPL no se puede enfrentar a la sociedad porque, posiblemente, será acusado de arruinarla.

- La disidencia entre Fateh y Hamas y la gran separación geográfica existente entre Cisjordania y la Franja de Gaza - cada vez mayor por culpa de la incesante creación de nuevos asentamientos de colonos israelíes - produjo un distanciamiento entre el MFPL y el MFPI, lo que causó más marginación y pobreza entre las mujeres de la base.

- El presupuesto destinado por la ANP para las instituciones relacionadas con temas de la mujer no es suficiente, en parte debido a que el déficit continúa en el presupuesto del Gobierno Palestino.

- Actualmente la coordinación y cooperación entre el MFPL y el MFPI son nulas. Normalmente, la cooperación era de bajo nivel entre ambos organismos debido a la gran diferencia ideológica, política y religiosa existente entre ellos.

- Las mujeres en los altos puestos de toma de decisiones no afectan ni benefician mucho a la situación actual de la mujer palestina en general, pues el MFPL carece de poder y de influencia para nombrar a las mujeres para que sean candidatas en las elecciones legislativas y en las de los consejos locales y municipales; por lo general son los partidos políticos los que confeccionan las listas y ellos prefieren elegir a una mujer obediente, no a una poderosa e influyente, para poder conseguir sus intereses en el Consejo Legislativo; en realidad no les importan nada los intereses y los problemas de las mujeres. Además, las mujeres que consiguen ser diputadas o miembros en los consejos locales se hallan oprimidas por los hombres; su voz no es escuchada por ellos, debido a la dominación masculina existente en el país. Como resultado, aunque lo deseen, ellas no pueden influir en los procesos del cambio social, político y económico. Además, la propia sociedad no acepta a la mujer en la arena política, especialmente en los altos cargos.

- Por todo lo dicho anteriormente, una parte de las mujeres del MFPL se marginan a sí mismas, y prefieren mantenerse pasivas por la frustración en la que viven, debido a la nefasta situación actual, a nivel económico, político y social.

- Además, no se puede olvidar la gran expansión del Islam político desde los años no- 
venta hasta ahora, que rechaza al MFPL y a su agenda totalmente. El aumento de la corriente conservadora y religiosa en la sociedad palestina en la actualidad impone muchas limitaciones y controles para la mujer.

- El MFPL desconoce, a ciencia cierta, si en la actualidad la sociedad palestina es islámica o laica. Tampoco sabe si su sistema económico es capitalista o no, ni si su economía es de mercado abierto. Todas esas dudas y desconocimientos hacen que los logros del MFPL sean fragmentados.

- Las mujeres líderes del MFPL ocupan más de un puesto a la vez; no comparten sus puestos con otras mujeres, ni se preocupan de fomentar la aparición de una nueva generación de mujeres activas y entusiastas para que enriquezcan y revitalicen el trabajo femenino.

- Se ha producido un retraso en el Movimiento Nacional Palestino (MNP) y, como consecuencia, también lo ha habido en el MFPL, porque éste constituye una parte del MNP. Por este motivo el desarrollo del MFPL sigue tan lento.

- Las mujeres que pertenecen a los partidos políticos se ocupan más de los intereses de su partido que de los beneficios del propio MFPL. En las elecciones ellas votan la lista electoral de su partido, y muy raramente votan a favor de la lista electoral femenina.

- Los dirigentes de la ANP, a pesar de crear el Ministerio de Asuntos de la Mujer, Unidades del Género y otras más, en realidad no adoptan convenientemente un proyecto efectivo que beneficie a la mujer; se escudan diciendo que es necesario aplazar todos los asuntos sociales hasta conseguir la liberación de Palestina. Siempre se concede la máxima prioridad al proyecto político nacional.

- Aunque es cierto que existen leyes que apoyan la situación de la mujer palestina en lo relacionado a la igualdad entre ambos sexos, a la hora de la verdad éstas no se aplican completamente por culpa de la mentalidad masculina dominante, y no sólo por la situación política.

A pesar de que debemos reconocer que las mujeres han alcanzado algunos logros, éstos se consideran como unos logros elementales y muy básicos, pues carecen de los medios efectivos y de desarrollo sostenibles para que puedan conseguir mejores resultados. Hasta ahora el movimiento femenino se halla desprovisto de armoniosas voces que sean capaces de hacer frente y de resistir las enormes dificultades y obstáculos a las que deben enfrentarse las mujeres en la sociedad palestina. Ésta sigue siendo una sociedad que refleja palpablemente una mentalidad masculina - y, en gran medida, machista -, lo que es nefasto para las mujeres. Necesitamos una sociedad con una mentalidad abierta, plural y diferente. El tamaño de la participación de la mujer en el proceso de toma de las decisiones y su acceso real a los altos cargos de las instituciones en el Gobierno Palestino no está en concordancia con el tamaño de los sacrificios, el sufrimiento y la larga lucha de la mujer palestina, codo con codo junto al hombre, en el momento de la lucha contra la ocupación israelí y, posteriormente, en su constante y casi ininterrumpida batalla. Ésa es una injusticia a la que hay que poner fin, no sólo para lograr el beneficio de la mujer, sino para el de toda la sociedad de Palestina, y más en los momentos cruciales que estamos viviendo.

\section{Bibliografía}

Abed Al-Hadi, Faiha: If They Gave Me the Choice: Histories of Daily Life of Palestinian Women During the Years of the Second Intifada (2000- 2003). Woman Centre for Juridical Assistance and Consulting. Ramallah (Palestine), 2004.

Abed Al-Hadi, Faiha: "Palestinian Woman and Memory". Workshop Papers about oral wording of her political intervention in the history of palestinian woman. April 1998. Department of Planning and Development of Woman Participation. Ministry of International Planning and Cooperation. Ramallah (Palestine), 2002.

Abu Fasha, Wasim: "Women in Local and Municipal Councils. Reality and Challenge". Journal of 
Life Water Springs. Edition 59. Twelfth Year. Association of Working Palestinian Woman for Development. Ramallah (Palestine), February 2011.

Ajrami, Ashraf Al-: "Woman and the Elections". Journal of Tasamuh (Tolerance). Centre for Human Rights Studies. Ramallah (Palestine), 2006.

Awad. Taleb: "The Palestinian Woman and Political Participation: Problems and Solutions". Ramallah (Palestine), 2005. www.awapp.org/wmview/php?ARTID $=722$.

Awad, Nesrin y Al-Shaf'ai, Kamal: Palestinian Woman in Political Parties Between Presence and Absence. Shams: ${ }^{1 s t}$ Edition. Centre of Human Rights y Democratic Participation. Ramallah (Palestine), 2010.

Balbisi, Majidah Al-: "Participation of Palestinian Woman in Political Life Depends on the Actual Political Situation, the Dissidence Make it Weak". Journal of Life Water Springs. Edition 58, Eleventh Year. Association of Working Palestinian Woman for Development. Ramallah (Palestine), October 2010.

Baqleh, Nadia Hajal: "Women and Local Council's Elections”. Journal of Woman Studies. Vol 3, 2005. Institute of Women Studies. Birzeit University. Ramallah (Palestine).

Daraghmeh, Ezat: Feminine Movement in Palestine (1903-1990). Centre for Studies. Jerusalem (Palestine), 1991.

Ghaiada, Emad: Palestinian Student Movement. Practice and Efficiency. ${ }^{\text {st }}$ edition. Muwatin: The Palestinian Institute for the Study of Democracy. Ramallah (Palestine), 2000.

Giacaman, Rita: "Looking for Strategies: Palestinian Feminine Movement in the New Era". Middle East Report. 186 (January- February 1994), pp. 22-26. Birzeit University. Ramallah (Palestine).

Highlights in Women Struggle: The Independent Intifada, the First Year. Association of Working Palestinian Woman for Development. Ramallah (Palestine), January 2002.

"In the Shadow of the Victory of Hamas: The Future of Feminine Movement, to Where?" Journal of Life Water Springs. Edition 44. Eighth Year. Association of Working Palestinian Woman for Development. Ramallah (Palestine), March 2006.

Jalgum, Mufid: Palestinian Feminine Movement in West Bank (1948- 1993). Master Thesis. AnNajah University. Nablus (Palestine), 2005.

Jayyusi, Walid Al-: "Woman and Political Participation". Journal of Life Water Springs. Edition 58, Eleventh Year. Association of Working Palestinian Woman for Development. Ramallah (Palestine), October 2010.

Khury, Rana: "Palestinian Woman and the Intifada". International Centre of Bethlehem Studies. Department of Women Studies. Bethlehem, 1995.

Kuttab, Eileen: Palestinian Woman: Change and Challenge. Institute of Woman Studies. Birzeit University. Ramallah (Palestine), 1981.

Kuttab, Eileen y Nida'a Abu-Odeh: "Palestinian Feminine Movement. Problems and Dialectical Issues". Journal of Woman Studies. Vol 3, 2004. Institute of Women Studies. Birzeit University. Ramallah (Palestine).

Labadi, Fadwa Al-: "Woman and the arena of political work". Journal of Woman Studies. Vol 3, 2004. Institute of Women Studies. Birzeit University. Ramallah (Palestine).

Nazzal, Reema Kettaneh: "Palestinian Woman, Peace and Armed Conflict". Journal of Life Water Springs. Edition 35. Sixth Year. Association of Working Palestinian Woman for Development. Ramallah (Palestine), March 2005.

Nazzal, Reema Kettaneh: "Participation between reality and appearance". Journal of Life Water Springs. Edition 58, Eleventh Year. Association of Working Palestinian Woman for Development. Ramallah (Palestine), October 2010.

Qazzaz, Hadeel Rezik: "Between Historical Legitimacy and Political Reality: Women in Palestinian Political System". Journal of Life Water Springs. Edition 39. Ninth Year. Association of Working Palestinian Woman for Development. Ramallah (Palestine), March 2005.

Qazzaz, Hadeel Rezik: "Deputies for Sensible Budget for Social Gender". Journal of Life Water Springs. Edition 42. Seventh Year. Association of Working Palestinian Woman for Development. Ramallah (Palestine), October 2005.

Report about the Activities of Imaginary Palestinian Parliament: Woman and Legislation for Central Religion (Jerusalem, Ramallah, Jericho) during the Period Between (1/8/1997- 
30/3/1998). Woman Centre for Juridicial Assistance and Consulting. Ramallah (Palestine).

"Second Legislative Elections from a Feminine Perspective". Journal of Life Water Springs. Edition 44. Eighth Year. Association of Working Palestinian Woman for Development. Ramallah (Palestine), March 2006.

\section{Entrevistas}

1.- Sra. Dalal Salameh: Ex-diputada de Fateh en el primer Consejo Legislativo Palestino. Realizada en una asociación femenina del campo de refugiados “Askar", de Nablus, el sábado 20 de abril de 2013.

2.- Con la Ministra de Asuntos de la Mujer Palestina, Sra. Rabiha Diab. Realizada en su despacho del Ministerio, en Ramallah, el lunes 6 de mayo de 2013.

3.- Sra. Hanan Emseh: Activista femenina, Directora de la Unidad del Género. Realizada en su despacho del Ministerio del Gobierno Local, en Ramallah, el miércoles 28 de noviembre de 2012

4.- Sra Khalida Jarra r: Diputada del FPLP en el Consejo Legislativo Palestino. Realizada en la Oficina del Frente Popular de la Liberación de Palestina (FPLP) de Ramallah, el jueves 14 de febrero de 2013.

5.- Dra. Najat Abo-Baker: Activista femenina y diputada de Fateh en el Consejo legislativo Palestino, realizada en lunes el 18 de marzo de 2013 en su despacho de Nablus.

Sr. Nehad Abu-Ghosh: líder y portavoz del Frente Democrático de Liberación de Palestina (FDLP), en la Sede del Frente de Ramallah. Realizada el martes el 2 de julio de 2013.

. 7.- Sra. Amani Al-Ramahi: Activista de Hamas, realizada en el Restaurante Al- Nur, en la ciudad de Al- Bireh, el 7 de julio de 2013.

8.- Sra. Majeda Fadda: Activista islámica. Realizada en su casa de Nablus, el martes 9 de julio de 2013.

9.- Sra. Soraida Abed Husein: Activista femenina y Directora de la Organización Femenina del Comité técnico de los Asuntos de la Mujer, realizada en su oficina de Ramallah, el lunes 10 de junio de 2013.

10.- Dra. Hanan Ashrawi, realizada en su despacho de la sede de la OLP de Ramallah, el miércoles 10 de julio de 2013 (primer día de Ramadan).

11.- Entrevista grabada con la Gobernadora de Ramallah y Al-Bireh, Dra. Laila Ghannam, en su despacho de la sede de la Provincia de Ramallah, el lunes 24 de junio de 2013.

12.- Sra. Sama Oweidah: Activista y líder femenina. Realizada en la sede de la Media Luna Roja de Ramallah, el lunes 9 de diciembre de 2013.

13.- Entrevista mantenida con la Ministra de Asuntos Sociales, Sra. Majida Al-Masri, en la Sede del Frente Democrático de Liberación de Palestina de Nablus, realizada el sábado 28 de abril de 2013. 